\title{
Financial Inclusion of Mexican Households in the Informal Financial System
}

\author{
Damara Alvarez Gonzalez¹, Antonio Ruíz Porras² \\ Universidad de Guadalajara
}

\begin{abstract}
We study econometrically the financial inclusion of Mexican households using socioeconomic determinants of access and use of savings and credit products. We focus on the main products existing in the informal financial system. We use micro data obtained from surveys of the years 2012, 2015 and 2018. The findings suggest that: 1) savings products have the biggest contribution for financial inclusion; 2) households headed by workers without benefits have less access to financial products; 3) demand-side determinants regarding households" heads, i.e., education, income and labor conditions, determine the degree of households' financial inclusion; 4) the supply-curve of financial products seems inelastic; and, 5) financial inclusion does not depend on the gender of the household head.
\end{abstract}

Keywords: Financial Inclusion, informal financial system, employee benefits, savings, credit, Mexican households. 